Dedicated to Prof. Billy E. Rhoades on the occasion of his $90^{\text {th }}$ anniversary

\title{
Iterating nonlinear contractive mappings in Banach spaces
}

\section{Zoran D. Mitrović, Stojan Radenović, Simeon Reich and Alexander J. ZASLAVSKI}

\section{ABSTRACT.}

We introduce a new class of nonlinear contractive mappings in Banach spaces, study their iterates and establish a fixed point theorem for them.

Acknowledgments. The third author was partially supported by the Israel Science Foundation (Grant no. 820/17), by the Fund for the Promotion of Research at the Technion and by the Technion General Research Fund.

\section{REFERENCES}

[1] Bisht, R. K., A note on the fixed point theorem of Górnicki, J. Fixed Point Theory Appl., 21 (2019), Article 54, 1-3, https:/ / doi.org/10.1007/s11784-019-0695-x

[2] Ćirić, Lj.,Some Recent Results in Metrical Fixed Point Theory, University of Belgrade, Beograd, Serbia, 2003

[3] Gabour, M., Reich, S. and Zaslavski, A. J., A generic fixed point theorem, Indian J. Math., 56 (2014), 25-32

[4] Kannan, R., Some results on fixed points, Bull Calcutta Math Soc., 60 (1968), 71-76

[5] Pant, A. and Pant, R. P., Fixed points and continuity of contractive maps, Filomat, 31 (2017), 3501-3506, https://doi.org/10.2298/FIL1711501P

[6] Reich, S., Some remarks concerning contraction mappings, Canad. Math. Bull., 14 (1971), 121-124

[7] Reich, S. and Zaslavski, A. J., Contractivity and genericity results for a class of nonlinear mappings, J. Nonlinear Convex Anal., 16 (2015), 1113-1122

[8] Reich, S. and Zaslavski, A. J., Existence of a unique fixed point for nonlinear contractive mappings, Mathematics, 8 (2020), Article 55, 1-7, https: / /doi:10.3390/math8010055

[9] Rhoades, B. E., A comparison of various definitions of contractive mappings, Trans. Amer. Math. Soc., 226 (1977), 257-290

Nonlinear Analysis Research Group

TON DUC THANG UNIVERSITY

Ho CHi Minh City, Vietnam

FACULTY OF MATHEMATICS AND STATISTICS

TON DUC THANG UNIVERSITY

Ho CHI Minh CiTY, VieTnAM

Email address: zoran.mitrovicetdtu.edu.vn

UNIVERSITY OF BELGRADE

FACULTY OF MECHANICAL ENGINEERING

Kraljice MARIJE 16, 11120 BeOGRAD 35, SERBIA

Email address: radensabeotel.rs

Received: 13.03.2020; In revised form: 09.06.2020; Accepted: 10.06.2020

2010 Mathematics Subject Classification. 47H09, 47H10.

Key words and phrases. Banach space, fixed point, iterate, nonlinear contractive mapping.

Corresponding author: Zoran D. Mitrović; zoran.mitrovic@tdtu.edu.vn 
Department OF MATHEMATICS

THE TECHNION-ISRAEL INSTITUTE OF TECHNOLOGY 32000 HAIFA, ISRAEL

Email address: sreichetechnion.ac.il

Email address: ajzasl@technion.ac.il 